\title{
Experimental and numerical analysis of dynamic compressive response of Nomex honeycombs
}

\author{
Yuwu Zhang ${ }^{\mathrm{a}}$, Tao Liu ${ }^{\mathrm{a}, \mathrm{b} *}$, Walid Tizani ${ }^{\mathrm{a}}$ \\ ${ }^{\text {a }}$ Centre for Structural Engineering and Informatics, Faculty of Engineering, University of \\ Nottingham, University Park, Nottingham, NG7 2RD, U.K \\ ${ }^{\mathrm{b}}$ Composites Research Group, Faculty of Engineering, University of Nottingham, University \\ Park, Nottingham, NG7 2RD, U.K \\ Email: Tao.Liu@nottingham.ac.uk, Tel: + 44 (0)115 7484059
}

\begin{abstract}
Lightweight phenolic resin-impregnated aramid paper honeycombs, commercially known as Nomex ${ }^{\circledR}$ honeycombs, are promising cores for sandwich structures in aerospace applications due to their high ratios of stiffness and strength to density. The out-of-plane compressive properties of the Nomex honeycombs have been widely investigated under quasi-static and low strain rates (up to $300 \mathrm{~s}^{-1}$ ). There is a need to understand the behaviour of this structure under higher strain rate compression. This will widen the applicability of these structures to more areas such as debris impact and other impacts which induce high strain rates. This paper reports the out-of-plane compressive responses of Nomex honeycombs subject to quasi-static loading and high strain rate dynamic loading up to $1500 \mathrm{~s}^{-1}$. The work involves experimental measurements and numerical modelling and validation. The compressive responses of the honeycombs were measured using a sensitive magnesium alloy Kolsky bar setup with front and back face impacts. The failure modes of the Nomex honeycombs were identified to be different under quasi-static and dynamic compressions. Under quasi-static compression, the honeycombs failed with local phenolic resin fracture after the elastic buckling of the honeycomb walls. For the dynamic compression, the honeycombs failed with the stubbing of cell walls at the ends of specimens. A finite element (FE) numerical model was devised and
\end{abstract}


validated with the experimental data. The FE model considered the strain rate effect of phenolic resin material. The model predictions were in good agreement with the experimental measurements and facilitated interpreting the out-of-plane compressive response of the Nomex honeycombs. It was shown that there was a linear compressive strength enhancement up to $30 \%$ from quasi-static to strain rate of $1500 \mathrm{~s}^{-1}$. The strength enhancement was governed by two mechanisms: the strain rate effect of the phenolic resin and inertial stabilization of the honeycomb unit cell walls, where $61 \%-74 \%$ of the enhancement was contributed by the inertial stabilization of the unit cell walls. In addition, it was shown that the impact method and initial imperfections had negligible effect on the compressive response of the Nomex honeycombs.

Keywords: Nomex honeycombs, dynamic compression, finite element analysis, inertial stabilization, strain rate effect

\section{Introduction}

Sandwich panels have been demonstrated to possess better resistance than monolithic panels in dynamic impact events [1-7], and the performance of sandwich structures is strongly dependent on the properties of their cores. Phenolic resin-impregnated aramid paper honeycombs, commercially known as Nomex ${ }^{\circledR}$ honeycombs, are promising cores of stiffnessdominated sandwich structure in aerospace applications due to their high ratio of stiffness and strength to density. The commercial Nomex honeycombs are composed of aramid paper layer [8] and phenolic resin coating [9-11] that both have excellent performance in terms of heat, flame and corrosion resistance. These honeycombs have weak in-plane strength but excellent out-of-plane strength under compression [12], which means the out-of-plane compressive behaviour of the honeycombs plays a dominate role in obtaining specific benefits. The out-ofplane mechanical properties of the Nomex honeycombs, in the present study as well as investigated by [13-18], have been compared with those of the other materials in the Ashby

material strength versus density map [19], see Fig. 1. In this figure, the solid line marked 
'Analytical' represents the maximum theoretical strength of the carbon fibre composite square honeycombs [20]. It indicates that the ratios of compressive strength to density of Nomex honeycombs are higher than many of the existing materials and structures as well as the carbon fibre composite square honeycombs [20, 21]. Marasco et al. [22] also reported that Nomex honeycombs had higher specific strength per unit mass than composite truss cores.

The quasi-static out-of-plane compressive behaviours of Nomex honeycombs have been extensively investigated. As reported in the literature [13, 18, 23-26], the Nomex honeycombs behaved linear elastically before achieving their peak compressive strengths and failed with local fracture of the coated phenolic resin. Liu et al. [13] evaluated the effects of key material parameters on the compressive strength of Nomex honeycombs using finite element simulations. They reported that the thickness, elastic modulus as well as the compressive strength of the phenolic resin coating had positive effects on the compressive strength of the honeycombs. Moreover, the height of honeycomb specimen had negligible effect on the compressive response. Liu et al. [25] also demonstrated numerically that the debonding imperfections of adhesive in double cell walls affected the out-of-plane compressive response of the honeycombs significantly, and that the debonding occured when the strength of the adhesive decreased. Keshavanarayan and Thotakuri [26] reported that the off-axis angle decreased the out-of-plane compressive collapse strength as well as the crush stress due to the structural instability.

Limited studies have been carried out on the dynamic out-of-plane compressive behaviours of Nomex honeycombs at low strain rates. Anagnostopoulos and Kim [16] experimentally investigated this behaviour using a Pendulum impactor system at strain rates up to $65 \mathrm{~s}^{-1}$. They found that the mechanical performance was not improved significantly with the increase of strain rate. Heimbs et al. [12] studied the effect of loading rate on the out-of-plane compressive response of Nomex honeycombs with a drop weight tester. They reported that the compressive 
strength of the honeycombs had a $30 \%$ enhancement for the strain rates up to $300 \mathrm{~s}^{-1}$ over the quasi-static.

Due to terrorist attacks, wars and other uncontrollable factors, there is a great need to model impact from fragments, ballistic, debris and others that induce high strain rates. Hence, there is an urgent need to understand the performance of Nomex honeycombs under such high strain rates. The dynamic compressive response of Nomex honeycombs under strain rates higher than $300 \mathrm{~s}^{-1}$ has not yet been reported. Also, as neither Pendulum impactor nor drop weight with load cell will be able to detect the compressive response of low-strength honeycombs under high strain rate impact, the experimental methodology needs to be developed for measuring the compressive response of Nomex honeycombs under high strain rates.

Although the studies on the strength enhancement mechanisms of similar types of honeycomb structures have been performed [27-32], there exists no related investigation on the Nomex honeycombs under dynamic compression. Harrigan et al. [27] experimentally investigated the compressive behaviour of the aluminium hexagonal honeycombs with an initial impact velocity up to $300 \mathrm{~ms}^{-1}$ using a Split Hopkinson Pressure Bar. They reported that the honeycombs failed with local instabilities and dynamic micro buckling of unit cell walls, and the inertial effect of the unit cell walls contributed to the enhancement of the collapse strength as well as the crushing stress. As proposed by Su et al. [28, 29], the parent material strain-rate effect and structural inertial effect played an equally important role on the dynamic enhancement behaviour of an energy-absorbing structure. Radford et al. [30], using experimental and numerical methods, identified that the dynamic compressive responses of stainless-steel square honeycombs were governed by three mechanisms: strain rate sensitivity of parent material, inertial stabilization of unit cell walls, and plastic wave propagation. Park et al. [31] investigated the compressive behaviour of carbon fibre-epoxy composite square honeycombs at strain rates up to $10^{4} \mathrm{~s}^{-1}$. By using a Kolsky pressure bar setup, they found that 
the failure mode of the honeycombs was governed by plastic buckling, and the strain rate sensitivity of the composites was due to that of the matrix. Finite element simulation is an effective method to reproduce the compressive response and identify the enhancement mechanisms of Nomex honeycombs. Such simulations at high strain rates, however, have not yet been reported.

The aim of the present study is to experimentally investigate the out-of-plane dynamic compressive behaviour at high strain rates (up to $1500 \mathrm{~s}^{-1}$ ) and develop a validated FE model of the Nomex honeycombs. In the remainder of this paper, the configuration of Nomex honeycomb specimen as well as the experimental protocols are described in Section 2, and the methodology for finite element simulation is developed in Section 3. The experimental measurements and finite element predictions are discussed in Section 4.

\section{Experimental protocols}

\subsection{Nomex honeycomb specimen}

This study investigates the Nomex honeycomb specimen, with density and out-of-plane thickness of $\rho=54 \mathrm{kgm}^{-3}$ and $H=10 \mathrm{~mm}$, respectively. The manufacturing process of the honeycombs is described as follow: the Nomex aramid paper layers made from random aramid fibres are stacked on top of each other and adhered by strips of thermoset epoxy adhesive at intervals. The hexagonal unit cells are formed by expanding the honeycombs along the stacking direction of the paper layers. Finally, the expanded geometry is impregnated into phenolic resin until the specific density of the honeycombs achieved [33]. Figures 2 (a) and (b) show the three-dimensional geometry of the Nomex honeycombs and the in-plane structure of its hexagonal unit cell, respectively. The scanning electron microscopic (SEM) image of the wall joints between the unit cells is shown in Fig. 2 (c). Throughout this paper, the wall joints are defined as the wall intersections of three adjacent unit cells. In addition, the axes of $\mathrm{x}, \mathrm{y}$ and $\mathrm{z}$ 
represent the directions of width $L_{W}$, length $L_{L}$ and out-of-plane thickness $H$ of the honeycomb specimen, respectively. The cell walls of the Nomex honeycombs are three-layer structures, i.e. an aramid paper layer is sandwiched by two phenolic resin layers on each surface of the aramid paper layer. The thicknesses of the single aramid paper layer and phenolic resin layer are $t_{f}=70 \mu \mathrm{m}$ and $t_{r}=12 \mu \mathrm{m}$, respectively, which are determined by the SEM image analysis. The characteristic cell size of the honeycombs is defined as $L_{C}=\sqrt{3} l=4.8 \mathrm{~mm}$, with $l$ as the edge length of the hexagonal unit cell, see Fig. 2 (b). The dimensionless relative density of the honeycombs can be defined as a function of cell wall thickness and edge length of the unit cell $[34,35]$

$$
\bar{\rho}=\frac{\rho}{\rho_{0}}=\frac{(l / 2+l+l / 2) t}{(\sqrt{3} / 2) l(l / 2+l / 2+l / 2)}=\frac{8 t}{3 \sqrt{3} l}
$$

where $\rho_{0}$ is the density of the cell walls of the Nomex honeycombs. $t\left(t=t_{f}+2 t_{r}\right)$ is the single-wall thickness of the unit cell geometry.

\subsection{Out-of-plane compression testing}

\subsubsection{Quasi-static compression testing}

The quasi-static out-of-plane compression tests were conducted using an Instron ${ }^{\circledR} 5581$ screw driven testing machine with a $50 \mathrm{KN}$ load cell. Two Linear Variable Differential Transformers (LVDT) installed symmetrically were employed for measuring the transverse deformation $\delta$ of honeycomb specimen, and the transverse force $F$ of the honeycombs was determined by the load cell. To ensure the compression was quasi-static, the honeycomb specimens were compressed in $\mathrm{z}$ direction at a constant displacement rate of $0.5 \mathrm{~mm} / \mathrm{min}$. The Nomex honeycomb specimens of in-plane length $L_{L}=65 \mathrm{~mm}$, width $L_{W}=65 \mathrm{~mm}$ and 175 unit cells are used. The nominal compressive stress and strain of the honeycomb specimens were taken 
as $\sigma=F / A$ and $\varepsilon=\delta / H$, respectively, with $A=65 \times 65 \mathrm{~mm}^{2}$ as the original crosssectional area of the honeycomb specimen. The average wall stress $\bar{\sigma}$ of the honeycombs can be defined in terms of nominal compressive stress $\sigma$ and relative density $\bar{\rho}$, i.e. $\bar{\sigma}=\sigma / \bar{\rho}$.

\subsubsection{Dynamic compression testing}

The honeycomb specimens of in-plane length $L_{L}=18 \mathrm{~mm}$, width $L_{W}=18 \mathrm{~mm}$ and 14 unit cells were used for dynamic out-of-plane compression tests. The dynamic out-of-plane compressive characteristics of the Nomex honeycombs were investigated in a series of direct impact tests using a strain-gauged Kolsky bar setup [30, 32, 36, 37]. The transient forces on the distal end and impacted end of the honeycomb specimens were measured using back face and front face impact tests, respectively. For the back face impact, a specimen attached to the impact end of the Kolsky bar was impacted centrally by a striker that was fired from a gun barrel, see Fig. 3 (a). For the front face impact, a specimen was adhered to the impact end of a striker that was fired from the gun barrel and impacted on the Kolsky bar, see Fig. 3 (b). The sketch of the three-dimensional honeycomb specimen at the point of impact is shown in Fig. 3 (c). In order to be able to measure the low compressive force of the Nomex honeycomb specimen and improve the response sensitivity of the measurement apparatus, the Kolsky bar made from magnesium alloy [38] (grade AZ61) with low elastic modulus of $E_{m}=45 \mathrm{GPa}$ and yield strength of $\sigma_{m}=130 \mathrm{MPa}$ was employed. The Kolsky bar had a length of $1 \mathrm{~m}$ and a diameter of $D_{m}=25.5 \mathrm{~mm}$. The Kolsky bar was in alignment with the gas gun and supported by four knife-edge friction-reducing Nylatron bearings. The impact end of the Kolsky bar was positioned $110 \mathrm{~mm}$ from the muzzle of the gas gun, and the bar was resisted at the distal end by an ACE MA 4757M self-adjusting shock absorber. The stress history of the specimen was measured by two diametrically opposite $120 \Omega$ TML foil strain gauges, which were placed 200 $\mathrm{mm}$ from the impact end of the Kolsky bar, of gauge length $1 \mathrm{~mm}$ in a half-Wheatstone bridge. 
The stress history, recorded as a voltage change, was amplified by a Vishay 2310B signal conditioning amplifier system and then output onto an Instek DPO3014 $100 \mathrm{MHz}$ 4-channel Digital Oscilloscope.

The strikers were made from M300 maraging steel (M-300) with elastic modulus of $E_{s}=210$ GPa and yield strength of $\sigma_{s}=1900 \mathrm{MPa}$, and had a diameter of $D_{s}=27.5 \mathrm{~mm}$. To ensure that the magnesium alloy Kolsky bar is elastically deformed under direct impact of the strikers (without specimen being placed between the striker and the Kolsky bar), the maximum impact velocity of the steel strikers, $v_{s-\max }$, can be calculated based on the elastic wave theory as follows:

$$
v_{s-\max }=\frac{\sigma_{m}\left(A_{s} \rho_{s} C_{s}+A_{m} \rho_{m} C_{m}\right)}{A_{m} \rho_{s} C_{s} \rho_{m} C_{m}}
$$

where $\rho_{m}=1800 \mathrm{kgm}^{-3}, C_{m}=\sqrt{\frac{E_{m}}{\rho_{m}}}$ and $A_{m}$ are the density, elastic wave velocity and cross sectional area of the magnesium alloy bar, respectively; $\rho_{s}=7800 \mathrm{kgm}^{-3}, C_{s}=\sqrt{\frac{E_{s}}{\rho_{s}}}$ and $A_{s}$ are the density, elastic wave velocity and cross sectional area of the steel strikers, respectively. It is calculated that the steel strikers of impact velocity more than $20 \mathrm{~ms}^{-1}$ can lead to the yield of the magnesium alloy Kolsky bar when there is no specimen between the striker and the Kolsky bar. In the present study, the initial velocity of the steel striker is no more than $15 \mathrm{~ms}^{-1}$ when impacting specimens. Two cylindrical strikers of different masses were employed in the impact tests in order to achieve the required striker velocities and provide constant velocity during the dynamic compression: a small striker of length $0.1 \mathrm{~m}$ and mass $0.463 \mathrm{~kg}$ was used for velocity range of $9 \leq v_{0} \leq 15 \mathrm{~ms}^{-1}$, and a larger striker of length $0.5 \mathrm{~m}$ and mass $2.3 \mathrm{~kg}$ was used for velocity range of $4.5 \leq v_{0} \leq 9 \mathrm{~ms}^{-1}$. The strikers were accelerated by a pressurised gas 
gun, in which strikers were propelled by compressed air. The gas gun had a barrel length of 3.5 $\mathrm{m}$, outer diameter of $40 \mathrm{~mm}$ and internal diameter of $28 \mathrm{~mm}$. The initial velocity of the striker was measured at the open end of the gun barrel via two laser gates and confirmed with a Phantom Mercury HS v12.1 high-speed camera. Typically, the frame rate and exposure time were 40,000 fps and $20 \mu \mathrm{s}$, respectively. As analysed in Section 4.2.1, the force equilibrium in Nomex honeycomb specimen has been achieved during the time scale in the dynamic compression tests.

\section{Finite element simulation}

\subsection{Finite element model}

Numerical simulations were conducted to simulate the quasi-static and dynamic compressive responses of the Nomex honeycombs using the explicit solver of the commercial finite element package ABAQUS ${ }^{\circledR}[39]$. The primary aims of the numerical investigation are:

- To develop an accurate three-dimensional finite element model to predict the compressive response of Nomex honeycomb structure under quasi-static and dynamic loading.

- To facilitate interpreting the role of the strain rate effect and inertial effect on enhancing the dynamic compressive strength of Nomex honeycomb structure.

- To understand the effects of the key parameters on the out-of-plane compressive response of the Nomex honeycombs.

In order to capture the wall buckling and failure of the honeycomb specimen, the aramid paper layer and phenolic resin layer were modelled separately, as shown in Fig. 4. Both the aramid paper layer and phenolic resin layer were modelled with 8-node 3D linear solid elements (C3D8R in ABAQUS notation) with reduced integration. The interaction of the interfaces between the aramid fibre layer and the phenolic resin layers was modelled as tie in ABAQUS 
notation, i.e. there is no relative displacement between the aramid fibre layer and the phenolic resin layers. To achieve converged solution, a mesh sensitivity analysis was carried out which determined that the element size of the honeycombs needed to be less than $0.15 \mathrm{~mm}$. The FE model of the honeycomb specimen was sandwiched by two rigid plates with 4-node discrete rigid elements (R3D4 in ABAQUS notation) in z direction. One of the rigid plates was fully constrained (all translational and rotational directions), and the other rigid plate was restricted to translate in $\mathrm{z}$ direction only.

For the quasi-static compression simulation, the movable rigid plate imposed loading on the honeycomb specimen with a constant velocity. To ensure the simulation was quasi-static, the kinetic energy was controlled to be under $5 \%$ of the total energy in the system. For the dynamic compression simulation, the movable rigid plate was associated with a mass point and an initial impact velocity that were identical to those of the strikers employed in the impact tests. In the back face impact, the honeycombs were tied to the fixed rigid plate and crushed by the movable rigid plate. In the front face impact, the honeycombs were tied to the movable rigid plate and moved together with the plate to impact on the fixed rigid plate. A general contact option with a friction coefficient of 0.05 was employed in all finite element calculations to simulate the interaction. A total of 134,000 elements were meshed for aramid paper layers, and 213,000 elements were meshed for phenolic resin layers.

\subsection{Constitutive models and material parameters}

\subsubsection{Constitutive model for aramid paper layer}

The constitutive model for the aramid paper layer included elasticity and rate independent plasticity. The elastic response of aramid paper layer was modelled using linear elasticity model for an isotropic solid with density $\rho_{f}=1075 \mathrm{kgm}^{-3}$, elastic modulus $E_{f}=2.36 \mathrm{GPa}$ 
and Poisson's ratio $v_{f}=0.3$. The $\mathrm{J} 2$ yield criterion in conjunction with isotropic hardening was used as the plasticity model of aramid paper layer.

There is a significant shortage of experimental study on the compressive behaviour of the aramid paper layer. Available research mainly focuses on the tensile behaviour. In the present study, the compressive behaviour of the aramid paper layer is assumed to be identical to the tensile behaviour [13]. As the compressive strength of aramid fibre is normally lower than the ultimate tensile strength [40], the assumption may overestimate the compressive strength of the aramid paper layer. Figure 5 (a) shows the tensile responses of the aramid paper layer in $0^{\circ}$ (paper roll direction), $90^{\circ}$ (transverse direction) and $45^{\circ}$, respectively, reported by Roy et al. [23]. The tensile strengths of the aramid paper layer in the three directions were much lower than the compressive strength of the phenolic resin layers. Therefore, the mechanical properties of aramid paper layer have limited effect on the compressive response of Nomex honeycombs. The numerical simulation conducted in this study using the experimental data in $45^{\circ}$ from Roy et al. [23] suggested this data gave the best fit for the experimental measurements of the Nomex honeycombs. Thus, the experimental data in $45^{\circ}$ obtained by Roy et al. [23] was used as the input to the constitutive model to specify the yield stress-plastic strain relation of the aramid paper layer. Here, we assume that the aramid paper layer is strain rate independent. The effect of strain rate dependency of aramid paper layer on the dynamic compressive response of Nomex honeycombs will be discussed in Section 4.2.5.

\subsubsection{Constitutive model for phenolic resin}

The constitutive model for the phenolic resin layer included elasticity and rate dependent plasticity [31]. Similar to the aramid paper layer, the elastic response of phenolic resin layer was modelled using linear elasticity model for an isotropic solid with density of $\rho_{r}=1100 \mathrm{~kg} \cdot \mathrm{m}^{-3}$, elastic modulus of $E_{r}=4.94 \mathrm{GPa}$ and Poisson's ratio of $v_{r}=0.3$. The $\mathrm{J} 2$ 
yield criterion combined with isotropic hardening was employed to model the plasticity. The compressive behaviour of the phenolic resin can be modelled as elastic-perfectly plastic before failure [41], as shown in Fig. 5 (a). The experimental data reported by Kilchert [41] was used as the input to the constitutive model to define the yield stress-plastic strain relation of the phenolic resin. The following yield ratio rate-dependent model [42] was employed to capture the rate dependency of the phenolic resin material.

$$
k=\frac{\sigma_{r p}}{\sigma_{r 0}}=C \&
$$

where $\&$ is the von Mises equivalent plastic strain rate $; k$ is the ratio of yield stress; $\sigma_{r 0}$ and $\sigma_{r p}$ are the compressive yield stresses of phenolic resin layer under quasi-static compression and dynamic compression, respectively; $C$ is the material constant that was obtained via calibration against dynamic testing of the Nomex honeycombs, and was determined to be $C=9.33 \times 10^{-4}$ s. Based on Eq. (3), the ratio of yield stress $k$ as a function of strain rate $\&$ at strain rates ranging from quasi-static value to $1500 \mathrm{~s}^{-1}$ is shown in Fig. 5 (b).

\section{Results and discussion}

\subsection{Quasi-static compressive response of Nomex honeycombs}

The experimentally measured and FE predicted out-of-plane quasi-static compressive responses of the Nomex honeycomb specimen are shown in Fig. 6 for nominal stress-strain curve. The FE predictions show a good agreement with the experimental measurements. The specimen showed a linear elastic mechanical behaviour before achieving the peak compressive stress and had an abrupt softening after achieving the peak stress, then displayed hardening followed by the densification at a nominal compressive strain of $\varepsilon=0.75$. The compressive strength of the Nomex honeycomb specimen was measured to be $\sigma_{S-\max }=3.09 \mathrm{MPa}$ at relative density $\bar{\rho}=0.051$, corresponding to the average peak wall stress $\bar{\sigma}=60.6 \mathrm{MPa}$. The 
compressive strength of the honeycomb sample was achieved at compressive strain $\varepsilon=0.03$. This is the strain that the compressive strength of the phenolic resin layer was achieved, see Fig. 5 (a). The compressive strength of phenolic resin was significantly higher than the strength of aramid paper layer. Hence, the compressive response of phenolic resin layer played a dominate role in the failure of the Nomex honeycombs under compression.

The FE predicted contours of von Mises stress within the specimen at selected strain levels, both with and without showing the phenolic resin layer, are shown in Fig. 7. The selected strain levels can be related to Fig. 6 (Points A, B, C and D), which range from elastic behaviour to post peak compressive stress behaviour. The numerical simulation suggested that the Nomex honeycomb walls first elastically buckled before achieving the compressive strength, as shown in Fig. 7 (a) at strain level A. At strain level B, the fracture of the phenolic resin layer was observed to be initiated at the mid-height area of the specimen. The fractured area was shown via the SEM image in Fig. 8 (a). For clarity, the three dimensional view of a unit cell taken from the middle of the specimen is shown in Fig. 7 (b). It can be seen that the stress at the junctions of the cell webs is higher than that in the middle of the cell webs owing to higher structural stability. At the hardening stage (strain levels $C$ and D), the aramid paper layers of the specimen folded at the location of the fractured phenolic resin layer. The SEM images of the top view of the honeycomb unit cell at the strain level D (Fig. 8 (b)) suggested that there was no significant damage at the junctions of unit cell webs.

\subsection{Dynamic compressive response of Nomex honeycombs}

\subsubsection{Back face impact}

The dynamic compressive response of the honeycomb specimen under back face impact is discussed next. The experimentally measured and FE predicted nominal compressive stresses versus the normalised time $v_{0} t / H$ at four selected impact velocities are shown in Fig. 9. Both 
experimental measurement and FE prediction confirmed that the strikers had constant velocity during the impact events. Hence, the compressive strain rates within the samples for the four selected impact velocities can be calculated as $150 \mathrm{~s}^{-1}$ (Fig. 9 (a)), $900 \mathrm{~s}^{-1}$ (Fig. 10 (b)), $1050 \mathrm{~s}^{-}$ ${ }^{1}$ (Fig. 9 (c)) and $1500 \mathrm{~s}^{-1}$ (Fig. 9 (d)). To ensure the accuracy of the measured compressive response of the honeycomb specimen, it is necessary to confirm the force equilibrium during the dynamic impact events. Using the elastic modulus and density of the aramid paper layer as well as the phenolic resin layer in section 3.2, we determined the longitudinal elastic wave speeds to be $c_{f}=\sqrt{\frac{E_{f}}{\rho_{f}}}=1482 \mathrm{~ms}^{-1}$ and $c_{r}=\sqrt{\frac{E_{r}}{\rho_{r}}}=2119 \mathrm{~ms}^{-1}$ for the aramid paper layer and phenolic resin layer, respectively. The measured compressive strength of the specimen was achieved at $76 \mu \mathrm{s} \leq \mathrm{t} \leq 111 \mu \mathrm{s}$ after impact. Hence, there were about 13 elastic wave reflections took place in the aramid paper layer and 19 elastic wave reflections took place in the phenolic resin layer when the compressive strength of the honeycombs achieved. Hence, it is concluded that the axial force equilibrium of the specimen was established when measuring the compressive strength.

As shown in Fig. 9, the dynamic compressive strengths under different strain rates are higher than that under quasi-static compression. Unlike the catastrophic failure under quasi-static compression, the dynamic compressive stress decreased smoothly after achieving the peak values. The compressive strengths of the honeycomb specimens obtained from the FE simulations agreed well with the experimental measurements. Due to the response time of the Kolsky bar setup [32], the normalised time $v_{0} t / H$ was different between experimental measurements and numerical simulations.

The montages of high-speed photographic images as well as the FE predictions at strain rates of $450 \mathrm{~s}^{-1}$ and $1500 \mathrm{~s}^{-1}$ are shown in Figs. 10 and 11, respectively, for selected time instants A, B ,C, D ( see Fig. 9) . 
The walls of honeycomb specimen buckled before the peak compressive strength achieved in the impact events, as shown in Fig. 10 (a) and Fig. 11 (a). When the peak compressive strength achieved, the concentrated stress transferred to the ends of the honeycomb specimens, as shown in Fig. 10 (b) and Fig. 11 (b). Then the unit cell walls stubbed against the faces of the Kolsky bar as well as the strikers. The folded locations of honeycomb walls were close to the ends of the specimen. The FE predictions showed that the maximum stress increased with the increase of impact velocity due to the strain rate sensitivity of the phenolic resin layer.

Figure 12 (a) shows the dependence of the dynamic peak wall stress $\bar{\sigma}_{D-\max }$ under back face impact normalised by the measured quasi-static peak wall stress $\bar{\sigma}_{S-\max }$ of honeycomb specimen upon the imposed strain rate $\&$. The peak compressive strengths of the honeycomb specimens increased linearly by approximately $30 \%$ from quasi-static to strain rate of $1500 \mathrm{~s}^{-}$ 1. According to the FE calculations under dynamic compression, the strength enhancement is achieved from the inertial stabilization of the honeycomb cell walls and the strain rate sensitivity of the phenolic resin layer. The FE model predicts the effects of these two enhancement mechanisms on the dynamic strength enhancement, as given in Fig. 12 (b). $\mathrm{P}_{\mathrm{ST}}$ (\%) and $\mathrm{P}_{\mathrm{IN}}(\%)$ are the percentages of strain rate effect of phenolic resin layer and inertial effect of unit cell walls in enhancing the dynamic compressive strength of the honeycombs, respectively. They are defined as

$$
\left\{\begin{array}{l}
\mathrm{P}_{\mathrm{ST}}=\frac{\sigma_{\mathrm{ST}}}{\sigma_{\mathrm{EN}}} \\
\mathrm{P}_{\mathrm{IN}}=\frac{\sigma_{\mathrm{IN}}}{\sigma_{\mathrm{EN}}}
\end{array}\right.
$$

where $\Delta \sigma_{\mathrm{EN}}$ is the enhanced compressive strength of Nomex honeycombs compared to the quasi-static compressive strength, defined as $\Delta \sigma_{\mathrm{EN}}=\sigma_{D-\max }-\sigma_{S-\max }$, with $\sigma_{S-\max }$ and $\sigma_{D-\max }$ as the quasi-static compressive strength and dynamic compressive strength of Nomex 
honeycombs, respectively; $\sigma_{\mathrm{ST}}$ and $\sigma_{\mathrm{IN}}$ are the enhanced compressive strengths caused by the strain rate effect of phenolic resin layer and inertial effect of the unit cell walls, respectively.

The relationship between the two factors, $\mathrm{P}_{\mathrm{ST}}$ and $\mathrm{P}_{\mathrm{IN}}$, is $\mathrm{P}_{\mathrm{ST}}+\mathrm{P}_{\mathrm{IN}}=100 \%$. The effect of the two factors on enhancing the dynamic compressive strength of Nomex honeycombs can be evaluated with and without considering the strain rate effect of phenolic resin in the FE calculations. It indicates that the inertial stabilization of cell walls, providing $61 \%-74 \%$ enhancement, plays a more significant role than the strain rate effect of phenolic resin material in enhancing the dynamic compressive strength of the Nomex honeycombs.

\subsubsection{Effect of the experimental method}

For the two impact configurations of back face and front face dynamic compressions, the plastic shock wave propagated oppositely within a honeycomb specimen. Hence, the dynamic compressive response of the honeycombs in back face impact configuration may be different from that in front face impact configuration. Figure 13 demonstrates that the compressive responses of the honeycombs with two impact methods are almost identical both at low impact velocity (Fig. 13 (a)) and high impact velocity (Fig. 13 (b)). The similar compressive responses under back face and front face compressions suggest that the specimens are in stress equilibrium over the deformation history. In addition, the finite element predictions conducted on the front face impact agreed well with the experimental measurements.

\subsubsection{Effect of strain rate sensitivity}

As discussed in Section 4.2.1, the strain rate sensitivity of the phenolic resin is one of the important factors in enhancing the compressive strength of the honeycomb specimen under dynamic compression. Figure 14 shows the comparison of the FE predicted dynamic compressive responses of the honeycomb specimens, with and without material rate dependency, under back face impact at strain rates of $450 \mathrm{~s}^{-1}$ and $1500 \mathrm{~s}^{-1}$. Though the phenolic 
resin has mild strain rate sensitivity, the peak compressive strengths of the honeycombs in rate dependent cases are just about 3\% and 10\% higher than those in rate independent cases at strain rates of $450 \mathrm{~s}^{-1}$ (Fig. 14 (a)) and $1500 \mathrm{~s}^{-1}$ (Fig. 14 (b)), respectively. This is due to the fact that the phenolic resin layer was thin and the aramid paper layer made from random aramid fibre $[33,41]$ was treated as a rate independent material.

\subsubsection{Effect of initial geometrical imperfections}

In order to investigate the effect of the initial geometrical imperfections on the compressive response of the Nomex honeycombs, quasi-static buckling eigenvalue analysis of honeycombs was conducted via FE predictions to obtain the eigenmode. As the aramid paper layers had voids among random fibres [41] and were far thicker than the phenolic resin layers, we assumed the initial imperfections were mainly from the aramid paper layers. The effect of the magnitude of the initial imperfections on the compressive response of Nomex honeycombs was investigated, and only the lowest eigenmode was considered in the FE calculations. The lowest eigenmode was employed to introduce perturbation to the mesh of the aramid paper layer, with maximum imperfection amplitude $10 \%$ and $20 \%$ of the single-layer thickness of the aramid paper layer. Figure 15 shows the FE predictions for quasi-static and dynamic compressions. It suggests that the initial imperfections slightly decrease the peak compressive strength of honeycomb specimen but have a limited effect on the compressive response. Hence, the FE

predicted compressive responses of the Nomex honeycombs are insensitive to the initial imperfections of amplitudes in the range 10\%-20\%.

\subsubsection{Effect of strain rate independency of aramid paper layer}

As discussed in Section 4.1, the compressive strain for the compressive strength of Nomex honeycombs was identical to that for the compressive strength of the phenolic resin layer, whereas the aramid paper layer didn't reach the peak strength of the material when the 
honeycombs failed. Hence, the failure of the aramid paper layer was governed by the failure of the phenolic resin layer. Moreover, the strength of the aramid paper layer used in the present FE prediction is significantly lower than the strength of the phenolic resin layer. Hence, the strain rate effect of the aramid paper layer on enhancing the compressive strength of Nomex honeycombs was weak. Warrior et al. [43] reported that the failure of random fibre reinforced composite was governed by the matrix failure under high strain rate compression. Park et al. [31] also reported that the strain rate dependency of the matrix contributed to the strain rate sensitivity of the carbon fibre composite square honeycombs. Thus the strain rate sensitivity of the phenolic resin layer played the dominate role in the strength enhancement contributed by the strain rate effect of material, and it was reasonable to assume that the aramid paper layer was strain rate independent.

\section{Conclusions}

The out-of-plane compressive responses of the Nomex honeycombs of density $54 \mathrm{~kg} . \mathrm{m}^{-3}$ and out-of-plane thickness $10 \mathrm{~mm}$ at strain rates ranging from quasi-static value to $1500 \mathrm{~s}^{-1}$ have been investigated. A series of dynamic impact tests were conducted with a magnesium alloy Kolsky bar setup. Finite element (FE) simulations were validated and used for facilitating the interpretation of the experimental measurements. The aramid paper layer and phenolic resin layer were modelled separately with different constitutive models.

Under quasi-static compression, the honeycomb specimen failed with catastrophic local fracture of phenolic resin layer after the elastic buckling of the honeycomb walls, which was followed by the aramid fibre layer folding at the location of the phenolic resin fracture. In addition, there was no significant damage at the wall joints as corroborated by the SEM image analysis. The compressive loading of the honeycombs before failure was principally carried by the coated phenolic resin layer. However, the aramid paper layer contributed to the high 
flexural rigidity of honeycomb walls that avoided the premature buckling of phenolic resin layer.

In the dynamic compression events, the honeycombs failed with stubbing of the cell walls at the ends of the specimens. Over the range of the strain rates applied from quasi-static to 1500 $\mathrm{s}^{-1}$, the peak compressive strength of the honeycombs increased linearly by approximately $30 \%$. The FE simulations demonstrated that two mechanisms enhanced the out-of-plane dynamic compressive strength: strain rate effect of the phenolic resin material and inertial stabilization effect of the honeycomb walls. The inertial stabilization of unit cell walls, contributing $61 \%$ $74 \%$ to the compressive strength enhancement of the Nomex honeycombs, played a more significant role. In addition, similar compressive responses of the honeycombs were obtained from two different impact tests, back face impact and front face impact.

Validated finite element simulation captured the experimental measurements reasonably. It demonstrated that the dynamic impact method as well as initial geometrical imperfections were insensitive to the out-of-plane compressive response of the Nomex honeycombs.

\section{Acknowledgments}

The authors acknowledge the support from the Royal Society through Research Grant Scheme as well as University of Nottingham Interdisciplinary Centre for Analytical Science (UNICAS) award. They also acknowledge the use of the High Performance Computing facility at the University of Nottingham for finite element calculations. The first author is grateful for the financial support from the China Scholarship Council (CSC) 


\section{References}

[1] McShane GJ, Radford DD, Deshpande VS, Fleck NA. The response of clamped sandwich plates with lattice cores subjected to shock loading. European Journal of Mechanics - A/Solids. 2006;25:215-29.

[2] Radford DD, Fleck NA, Deshpande VS. The response of clamped sandwich beams subjected to shock loading. International Journal of Impact Engineering. 2006;32:968-87.

[3] Radford DD, McShane GJ, Deshpande VS, Fleck NA. The response of clamped sandwich plates with metallic foam cores to simulated blast loading. International Journal of Solids and Structures. 2006;43:2243-59.

[4] Uth T, Deshpande VS. Response of clamped sandwich beams subjected to high-velocity impact by sand slugs. International Journal of Impact Engineering. 2014;69:165-81.

[5] Fleck NA, Deshpande VS. The Resistance of Clamped Sandwich Beams to Shock Loading. Journal of Applied Mechanics. 2004;71:386-401.

[6] Liu T, Fleck NA, Wadley HNG, Deshpande VS. The impact of sand slugs against beams and plates: Coupled discrete particle/finite element simulations. Journal of the Mechanics and Physics of Solids. 2013;61:1798-821.

[7] Russell BP, Liu T, Fleck NA, Deshpande VS. The soft impact of composite sandwich beams with a square-honeycomb core. International Journal of Impact Engineering. 2012;48:65-81. [8] Bourbigot S, Flambard X. Heat resistance and flammability of high performance fibres: A review. Fire and Materials. 2002;26:155-68.

[9] Zhou J, Yao Z, Chen Y, Wei D, Wu Y, Xu T. Mechanical and thermal properties of graphene oxide/phenolic resin composite. Polymer Composites. 2013;34:1245-9.

[10] Shafizadeh JE, Seferis JC. Characterization of phenolic resin for composite honeycomb applications. ICCM-12. Pairs1999. 
[11] Kandola BK, Krishnan L, Deli D, Ebdon JR. Blends of unsaturated polyester and phenolic resins for application as fire-resistant matrices in fibre-reinforced composites. Part 2: Effects of resin structure, compatibility and composition on fire performance. Polymer Degradation and Stability. 2015;113:154-67.

[12] Heimbs S, Schmeer S, Middendorf P, Maier M. Strain rate effects in phenolic composites and phenolic-impregnated honeycomb structures. Composites Science and Technology. 2007;67:2827-37.

[13] Liu L, Wang H, Guan Z. Experimental and numerical study on the mechanical response of Nomex honeycomb core under transverse loading. Composite Structures. 2015;121:304-14. [14] Aktay L, Johnson AF, Kröplin B-H. Numerical modelling of honeycomb core crush behaviour. Engineering Fracture Mechanics. 2008;75:2616-30.

[15] Seemann R, Krause D. Numerical modelling of Nomex honeycomb cores for detailed analyses of sandwich panel joints. 11th World Congress on Computational Mechanics. Barcelona, Spain2014.

[16] Anagnostopoulos K, Kim H. Phenomenological investigation of Nomex core damage mechanics in honeycomb sandwich panels under transverse impact and quasi-static loading. 31st Annual Technical Conference of the American Society for Composites. Virginia, USA2016.

[17] Asprone D, Auricchio F, Menna C, Morganti S, Prota A, Reali A. Statistical finite element analysis of the buckling behavior of honeycomb structures. Composite Structures. 2013;105:240-55.

[18] Zhang J, Ashby MF. The out-of-plane properties of honeycombs. International Journal of Mechanical Sciences. 1991;34:475-89.

[19] Ashby MF, Bréchet YJM. Designing hybrid materials. Acta Materialia. 2003;51:5801-21. 
[20] Russell BP, Deshpande VS, Wadley HNG. Quasi-static deformation and failure modes of composite square honeycombs. Journal of Mechanics of Materials and Structures. 2008;3:1315-40.

[21] Russell BP, Liu T, Fleck NA, Deshpande VS. Quasi-Static Three-Point Bending of Carbon Fiber Sandwich Beams With Square Honeycomb Cores. Journal of Applied Mechanics. 2011;78:031008.

[22] Marasco AI, Cartié DDR, Partridge IK, Rezai A. Mechanical properties balance in novel Z-pinned sandwich panels: Out-of-plane properties. Composites Part A: Applied Science and Manufacturing. 2006;37:295-302.

[23] Roy R, Park S-J, Kweon J-H, Choi J-H. Characterization of Nomex honeycomb core constituent material mechanical properties. Composite Structures. 2014;117:255-66.

[24] Foo CC, Chai GB, Seah LK. Mechanical properties of Nomex material and Nomex honeycomb structure. Composite Structures. 2007;80:588-94.

[25] Liu L, Meng P, Wang H, Guan Z. The flatwise compressive properties of Nomex honeycomb core with debonding imperfections in the double cell wall. Composites Part B: Engineering. 2015;76:122-32.

[26] Keshavanarayana S, Thotakuri MV. Off-axis compression behaviour of honeycomb core in WT-plane. International Journal of Crashworthiness. 2009;14:173-81.

[27] Harrigan JJ, Reid SR, Peng C. Inertia effects in impact energy absorbing materials and structures. International Journal of Impact Engineering. 1999;22:955-79.

[28] Su XY, Yu TX, Reid SR. Interial-sensitive impact energy-absorption structures. Part I: effect of inertia and elasticity. International Journal of Impact Engineering. 1995;16:651-72. [29] Su XY, Yu TX, Reid SR. Inertia-sensitive impact energy-absorbing structures. Part II: effect of strain rate. International Journal of Impact Engineering. 1995;16:673-89. 
[30] Radford DD, McShane GJ, Deshpande VS, Fleck NA. Dynamic Compressive Response of Stainless-Steel Square Honeycombs. Journal of Applied Mechanics. 2007;74:658-67.

[31] Park S, Russell BP, Deshpande VS, Fleck NA. Dynamic compressive response of composite square honeycombs. Composites Part A: Applied Science and Manufacturing. 2012;43:527-36.

[32] Liu T, Turner P. Dynamic compressive response of wrapped carbon fibre composite corrugated cores. Composite Structures. 2016.

[33] Abrate S, Castanié B, Rajapakse YDS. Dynamic Failure of Composite and Sandwich Structures. New York: Springer, 2012.

[34] L.J. Gibson MFA. Cellular solids: structure and properties. Cambridge, UK: Cambridge University Press, 1997.

[35] Penado FE. Effective Elastic Properties of Honeycomb Core with Fiber-Reinforced Composite Cells. Open Journal of Composite Materials. 2013;03:89-96.

[36] Kolsky H. An Investigation of the Mechanical Properties of Materials at very High Rates of Loading. Proceedings of the Physical Society Section B. 1949;62:676-700.

[37] Zhang Y, Liu T, Ren H, Maskery I, Ashcroft I. Dynamic compressive response of additively manufactured AlSi10Mg alloy hierarchical honeycomb structures. Composite Structures. 2018.

[38] Park S, Uth T, Fleck NA, Wadley HNG, Deshpande VS. Sand column impact onto a Kolsky pressure bar. International Journal of Impact Engineering. 2013;62:229-42.

[39] ABAQUS. ABAUQS analysis user's manual, Version 6.14, ABAQUS, Inc. 2014.

[40] W J, Jr D, Newell JA. Characterization of structural changes in thermally enhanced Kevlar-29 fiber. Journal of Applied Polymer Science. 2003;91:417-24.

[41] Kilchert SV. Nonlinear finite element modelling of degradation and failure in folded core composite sandwich structures: University of Stuttgart, 2013. 
[42] NagarajaRao N, Lohrmann M, Tall L. Effect of strain rate on the yield stress of structural steel. ASTM Journal of Materials. 1966;1:1684-737.

[43] Warrior NA, Fernie R, Jones IA. High strain rate tensile and compressive testing of braided composite materials. 2003 SEM Annual Conference \& Exposition on Experimental and Applied mechanics. Charlotte, North Carolina2003. 


\section{Figure Caption}

Figure 1. A compressive strength versus density map for engineering materials [19], including the measured properties of Nomex honeycombs in the current study as well as investigated by [13-18] which were denoted by a solid hexagon and hollow hexagons. The solid line represents the maximum theoretical strength of composite square honeycombs [20], which falls into the high specific strength gap at low densities.

Figure 2. (a) Three-dimensional sketch of the Nomex honeycombs and (b) the in-plane sketch of a unit cell. (c) The scanning electron microscopic (SEM) photograph at the wall joint.

Figure 3. Sketch of the Magnesium alloy Kolsky bar setup in (a) back face and (b) front face impact tests, and (c) the three-dimensional sketch at the impact point. All dimensions are in mm.

Figure 4. (a) Finite element (FE) model of the honeycomb unit cell and (b) the wall joint.

Figure 5. (a) The stress-strain relations of aramid paper layer [24] and compressive properties of phenolic resin layer [41]. (b) The yield ratio rate-dependent model of phenolic resin layer.

Figure 6. Experimental measured and FE predicted stress-strain relationships of the Nomex honeycombs of density $\rho=54 \mathrm{~kg} \cdot \mathrm{m}^{-3}$ and out-of-plane thickness $\mathrm{H}=10 \mathrm{~mm}$ under quasistatic compression.

Figure 7. (a) Montage of the Nomex honeycombs under quasi-static compression obtained from experimental measurements and numerical simulations, and (b) three-dimensional view of the unit cell taken from the middle of the FE honeycomb model at strain level B. The strain levels A-D refer to the Points A-D in Fig. 6.

Figure 8. Scanning electron microscopic (SEM) photographs of (a) the honeycomb wall at strain level B, and (b) top view of the honeycomb unit cell after quasi-static compression at 
strain level D, respectively. It is noted that the left image in (a) was taken by normal camera. The strain levels B and D refer to the Points B and D in Fig. 6, respectively.

Figure 9. Nominal compressive stress as a function of normalised time $v_{0} t / H$ obtained from the back face impact tests at different strain rates of (a) $450 \mathrm{~s}^{-1}$, (b) $900 \mathrm{~s}^{-1}$, (c) $1050 \mathrm{~s}^{-1}$ and (d) $1500 \mathrm{~s}^{-1}$, respectively.

Figure 10. Montage of high speed photographs showing the deformation patterns of the Nomex honeycombs under back face impact at strain rate of $450 \mathrm{~s}^{-1}$ obtained from experiment and numerical simulations. The time instants A-D refer to the Points A-D in Fig. 9 (a).

Figure 11. Montage of high speed photographs showing the deformation patterns of the Nomex honeycombs under back face impact strain rate of $1500 \mathrm{~s}^{-1}$ obtained from experiment and numerical simulations. The time instants A-D refer to the Points A-D in Fig. 9 (d).

Figure 12. (a) The dynamic peak wall stress of the Nomex honeycombs under back face impact normalised by the experimentally measured quasi-static peak wall stress as a function of strain rate \& , and (b) the contributions of two key factors, strain rate effect of phenolic resin and inertial stabilization of unit cell walls, to the compressive strength enhancement of the Nomex honeycombs under dynamic compression.

Figure 13. Nominal compressive stress of the Nomex honeycombs as a function of $v_{0} t / H$ at selected impact velocities obtained from back face and front face experimental measurements as well as FE simulations.

Figure 14. FE study on the effect of strain rate sensitivity of the phenolic resin material at strain rates (a) $450 \mathrm{~s}^{-1}$ and (b) $1500 \mathrm{~s}^{-1}$.

Figure 15. FE predictions of the Nomex honeycombs with initial imperfections under (a) quasistatic compression and (b) back face impact at strain rate $1500 \mathrm{~s}^{-1}$. 


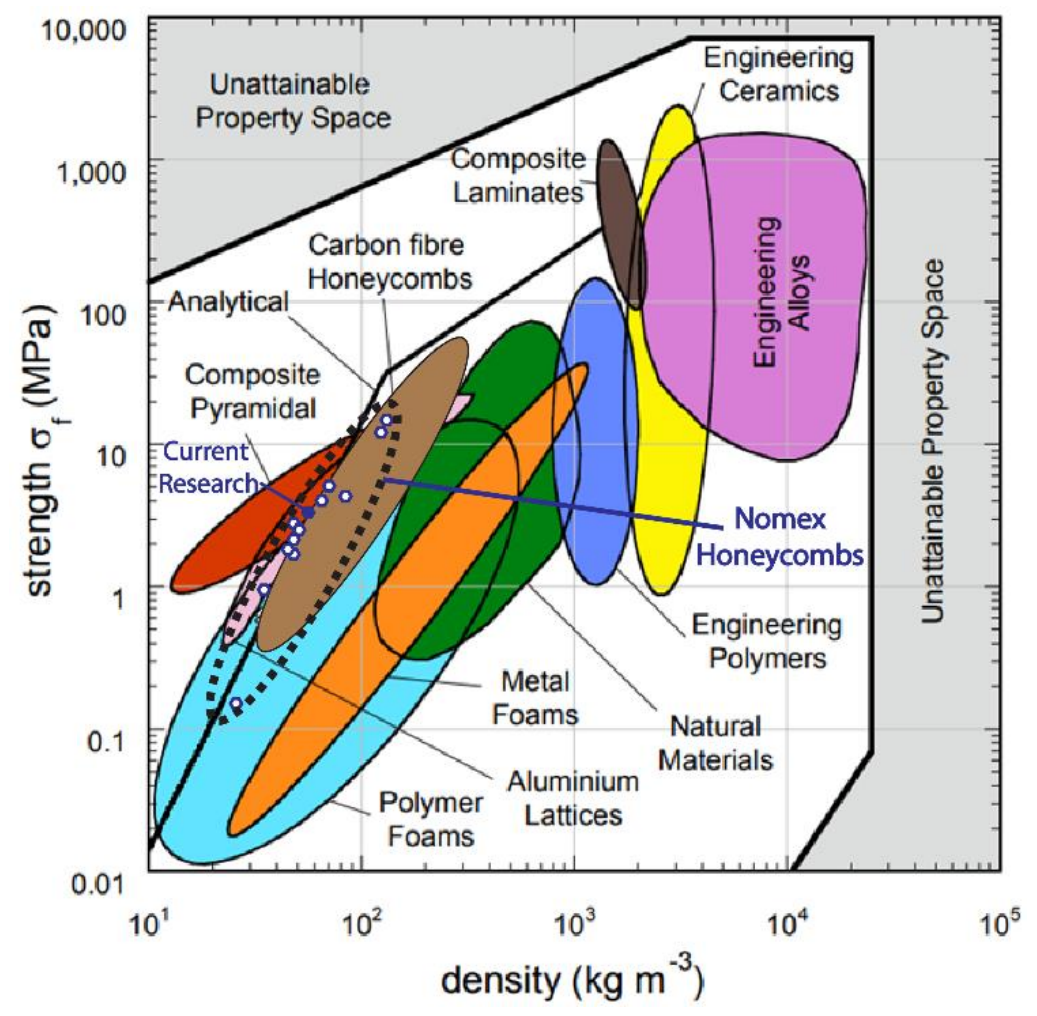

Figure 1

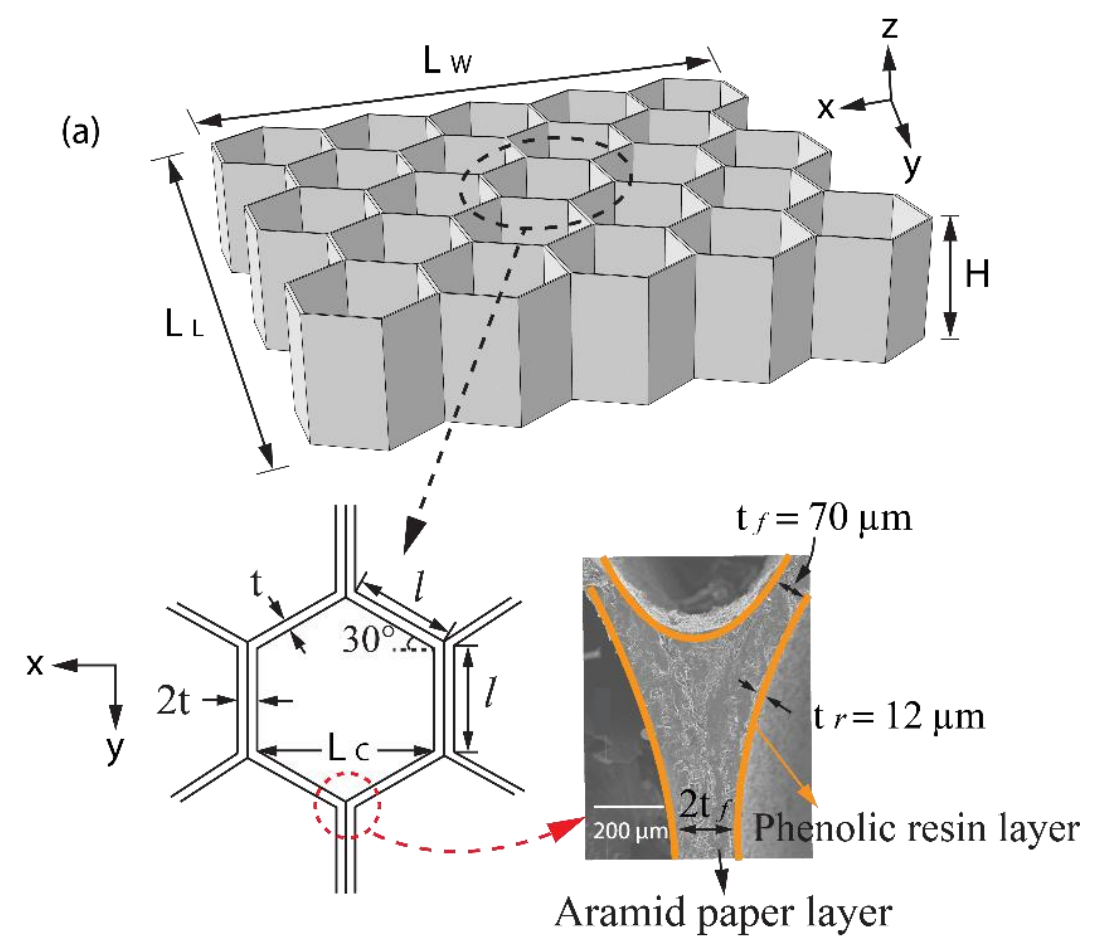

(b)

(c)

Figure 2 
(a) Two strain gauges on diametrically opposite sides

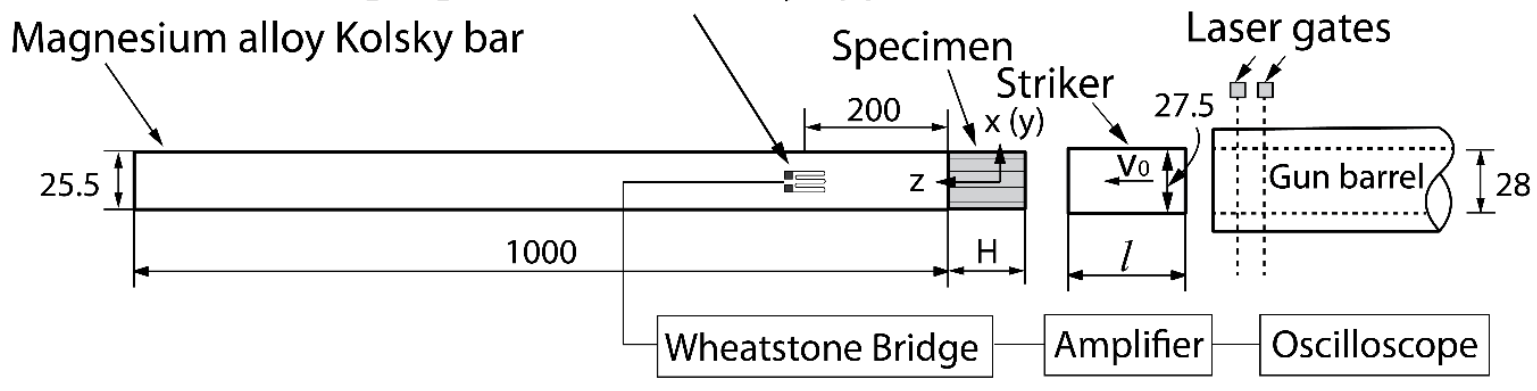

(b)

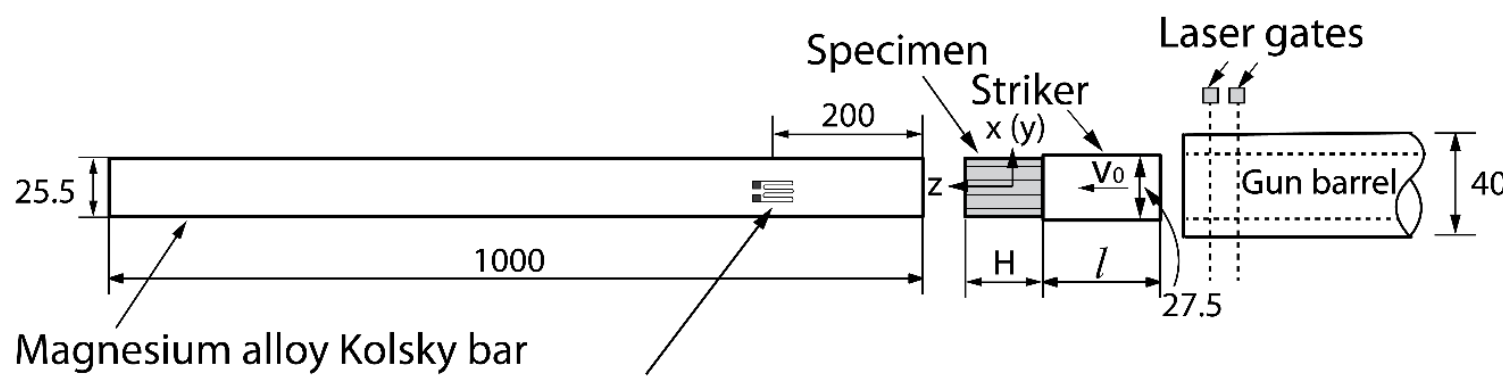

Two strain gauges on diametrically opposite sides (c)

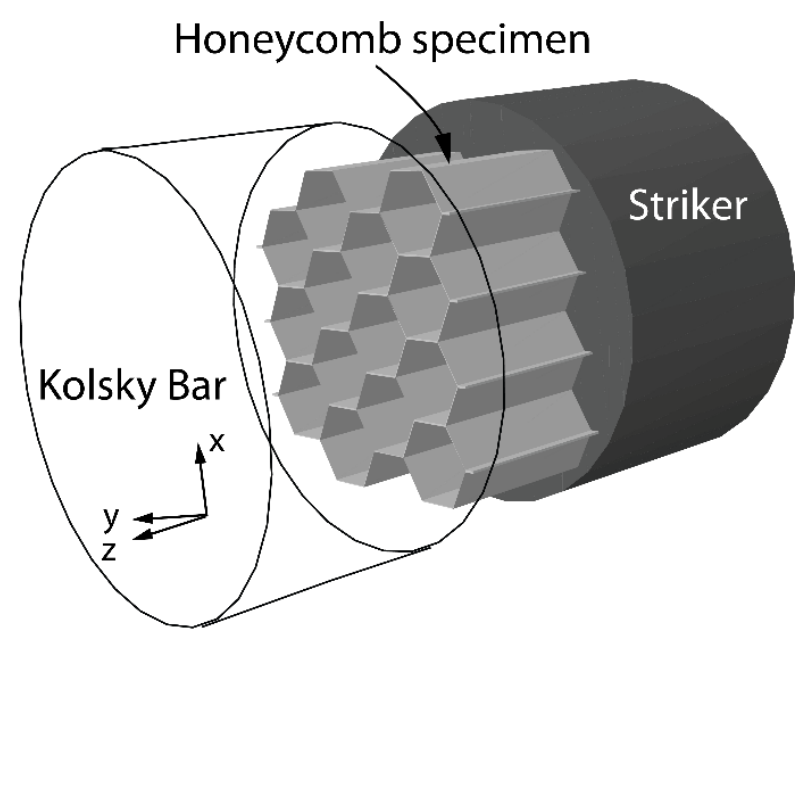

Figure 3 


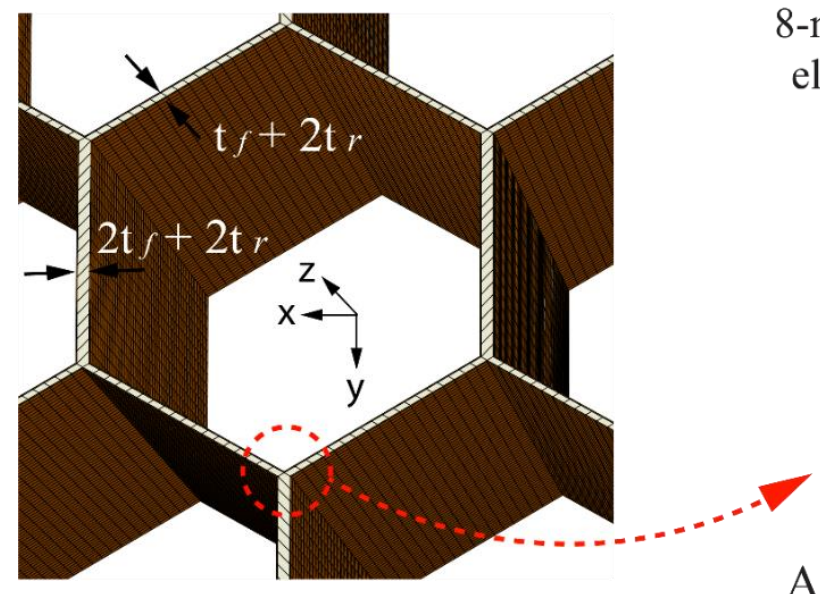

(a) 8-node linear solid

elements-C3D8R

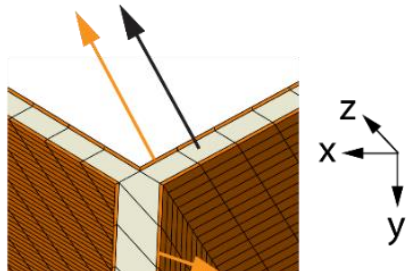

Phendic resin layer

Aramid paper layer

(b)

Figure 4
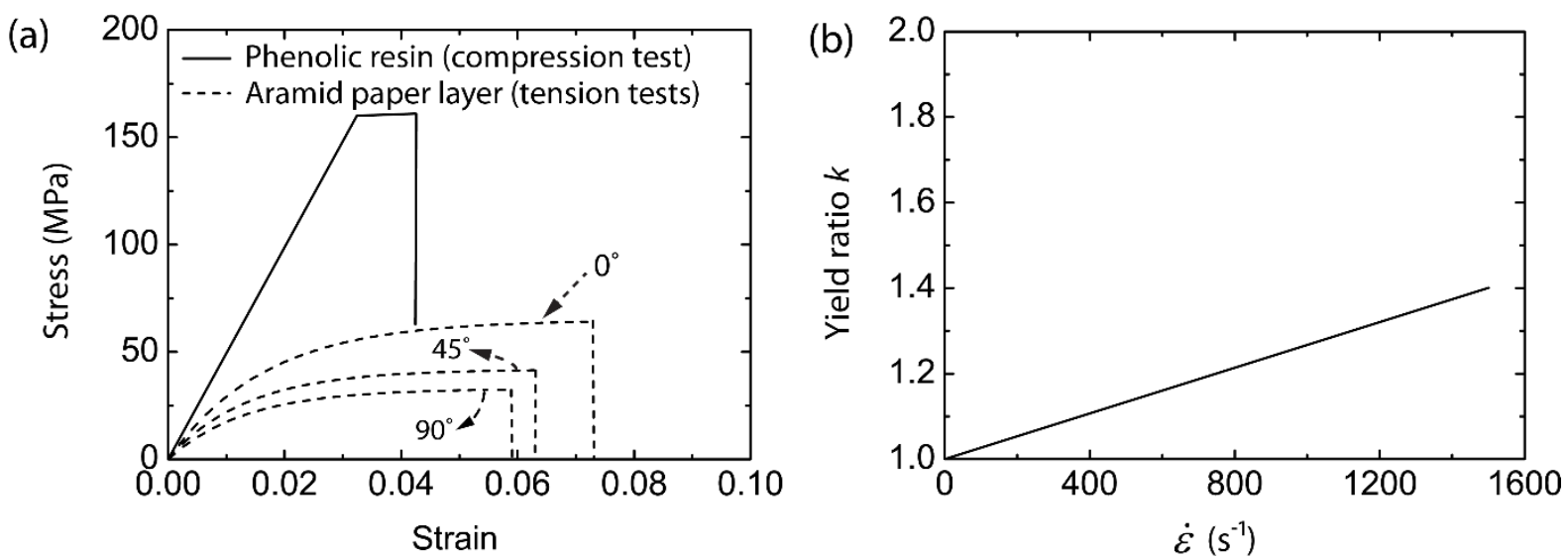

Figure 5

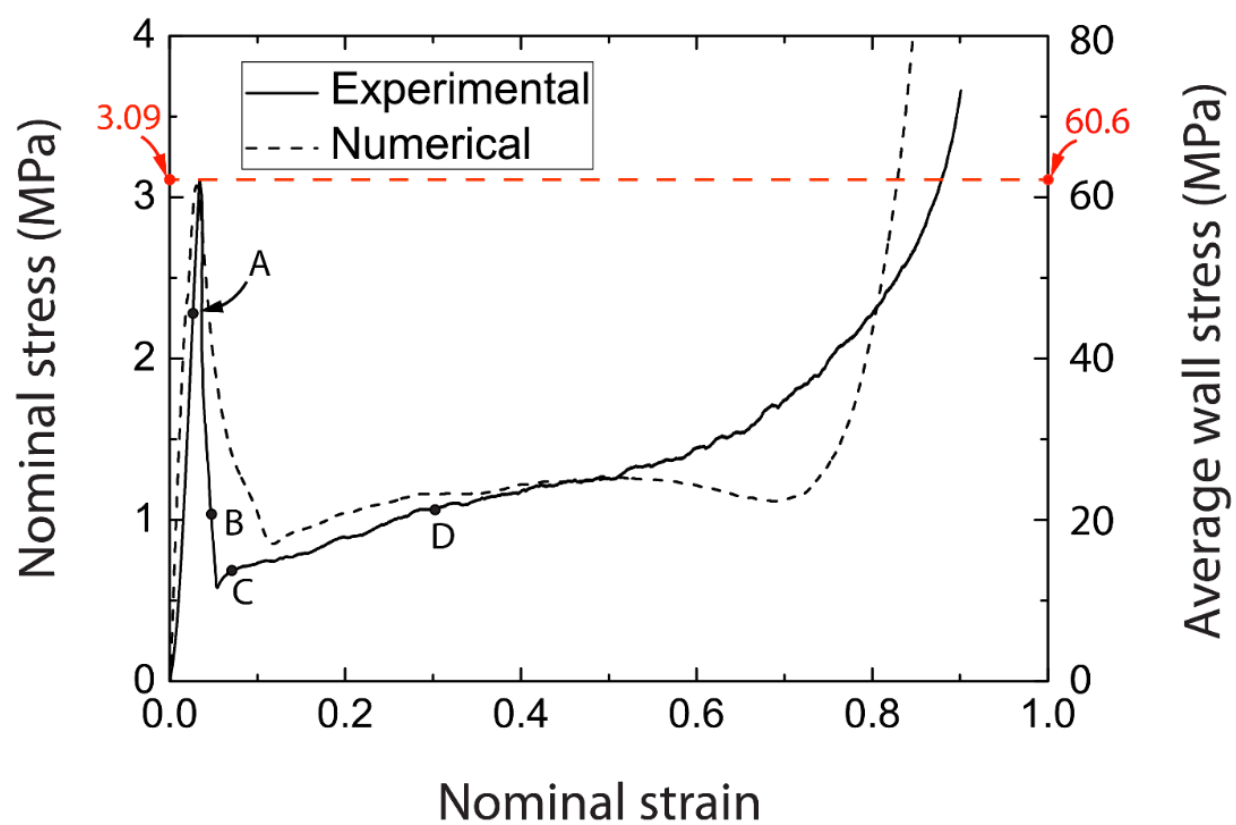

Figure 6 
Experiment

A

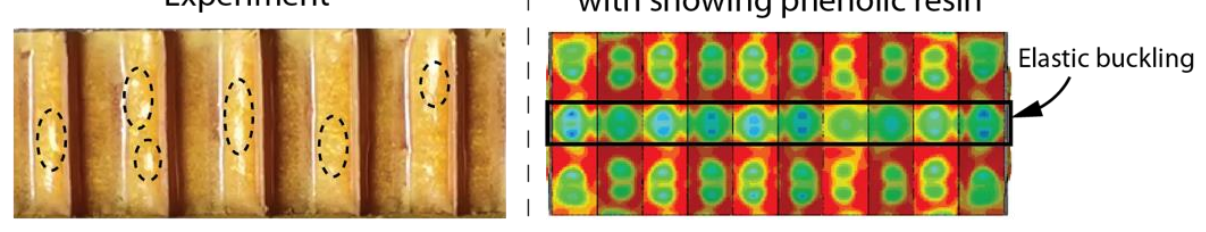

B

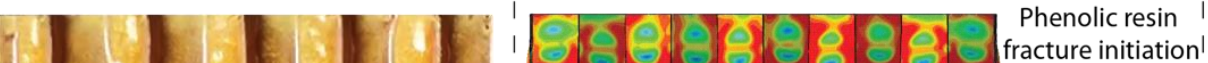

\begin{tabular}{|l|l|l|l|l|}
\hline & 1 & 1 & & \\
\hline
\end{tabular} 1. . . 1.

C

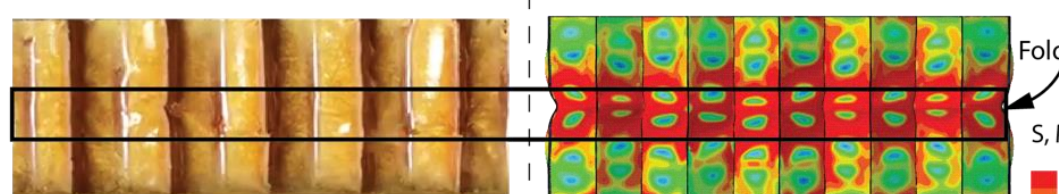

D

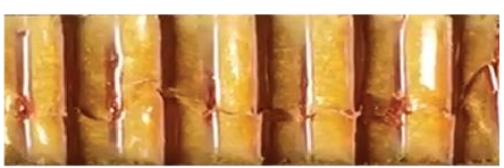

Wall buckling

Mises (kPa)

Mises $(\mathrm{kPa})$
$+1.610 \mathrm{e}+05$

$+1.610 \mathrm{e}+05$
$+1.377 \mathrm{e}+05$

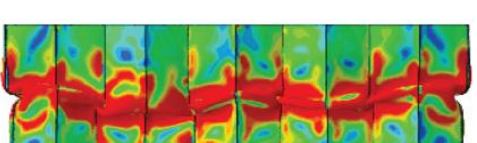

$+1.144 \mathrm{e}+05$

$+9.112 \mathrm{e}+04$

$+6.782 \mathrm{e}+04$
$+4.453 \mathrm{e}+04$

$+4.453 \mathrm{e}+04$ II

(a)
II without showing phenolic resin
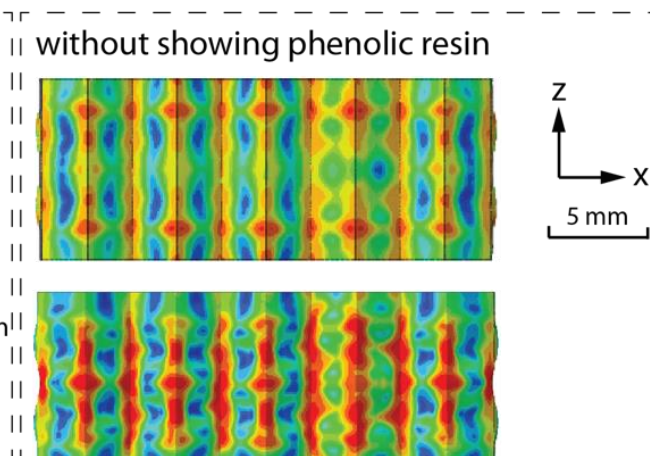

"I

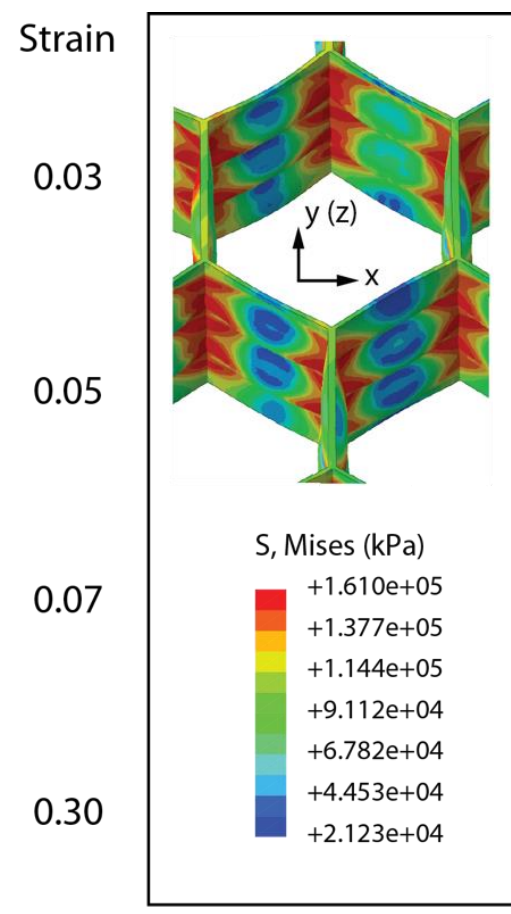

(b)

Figure 7 


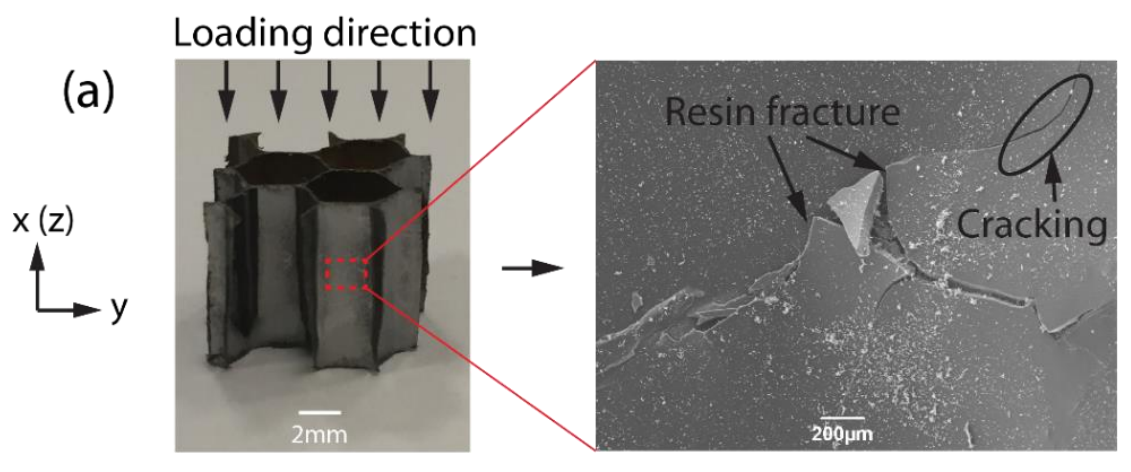

Strain level B
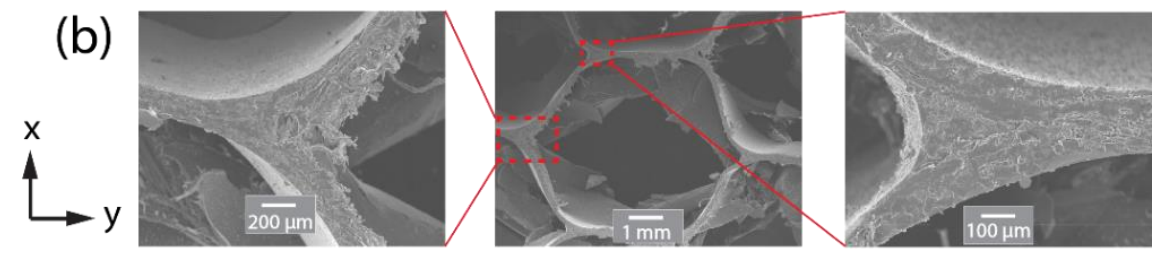

Strain level D

Figure 8

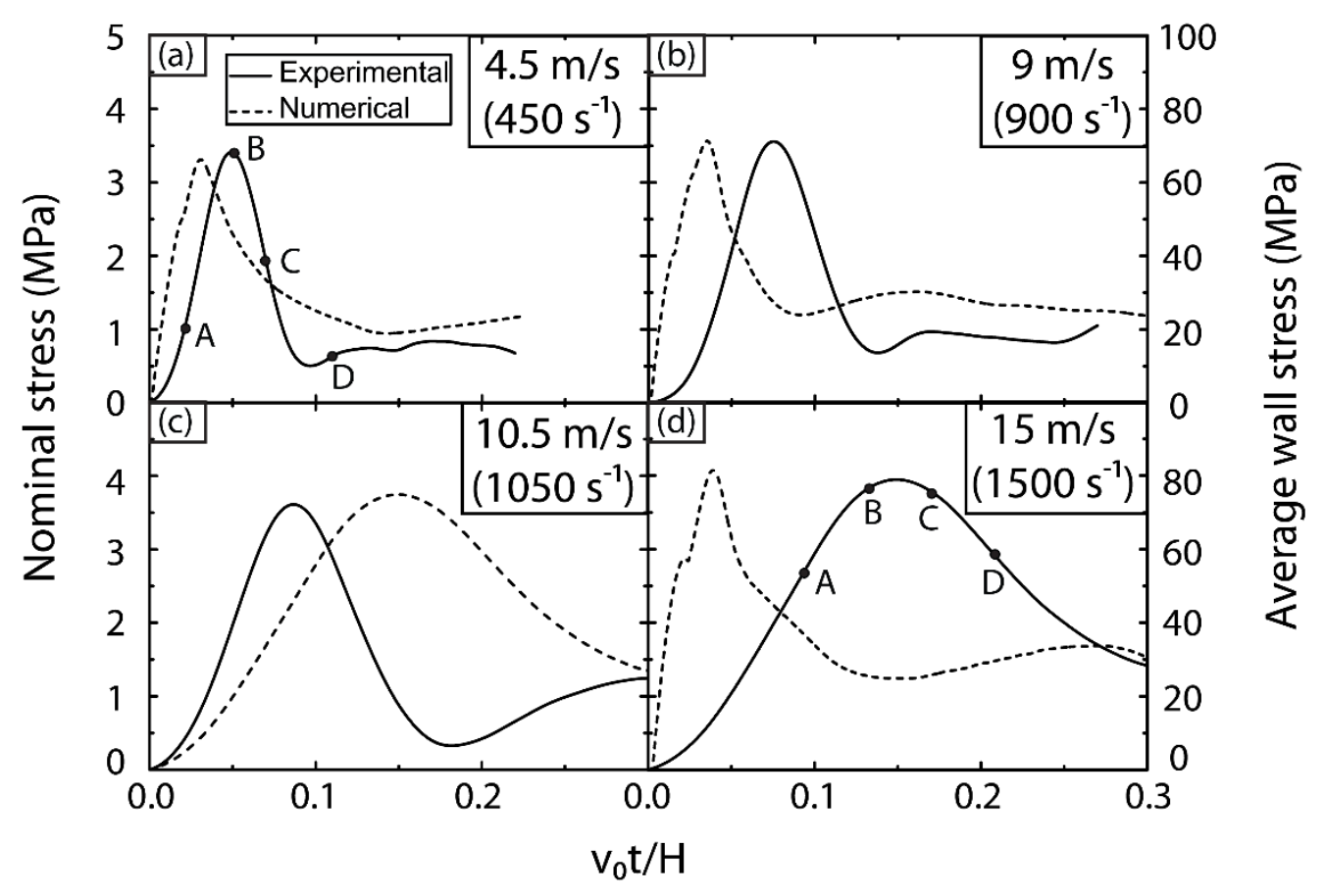

Figure 9 

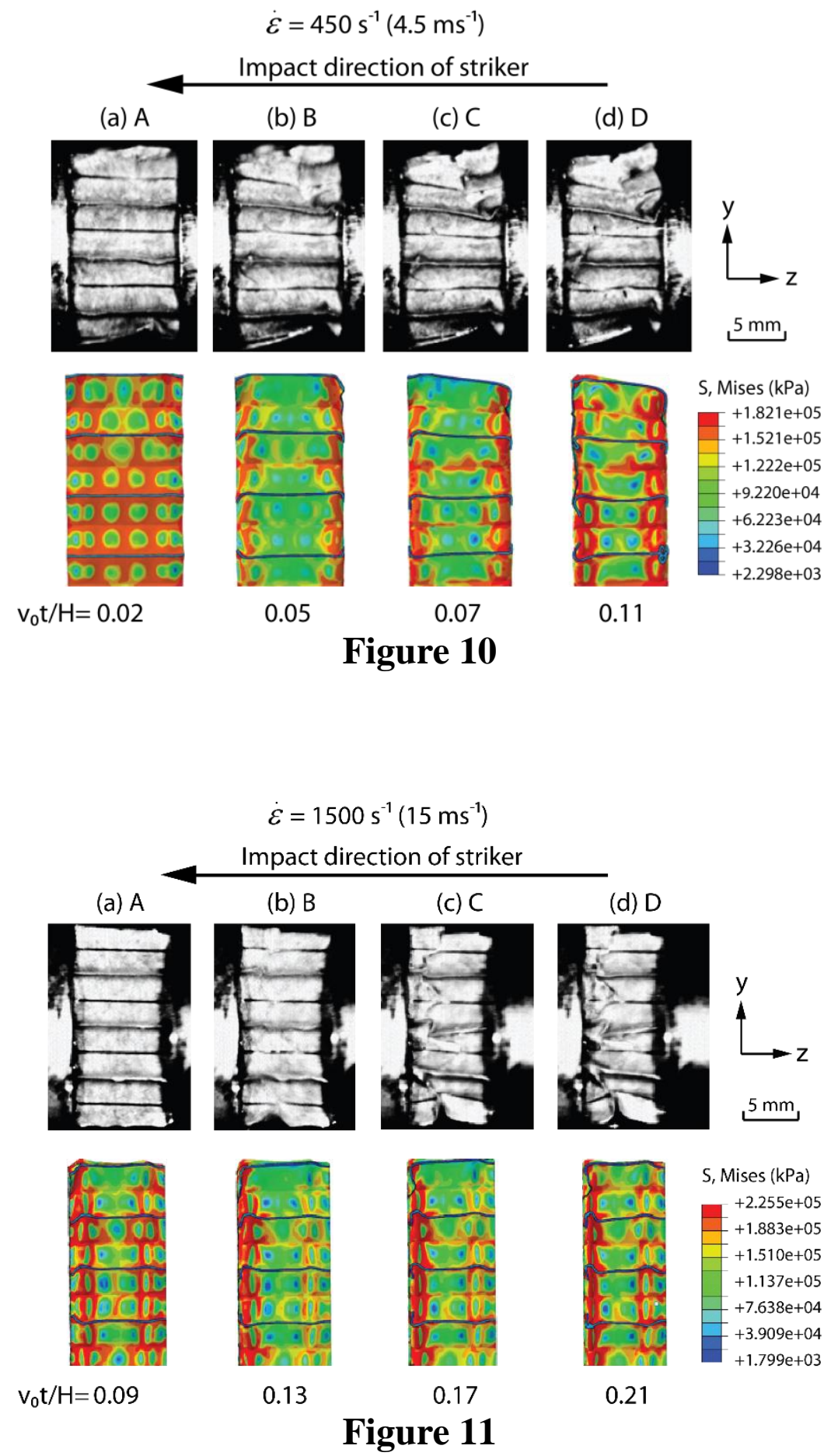

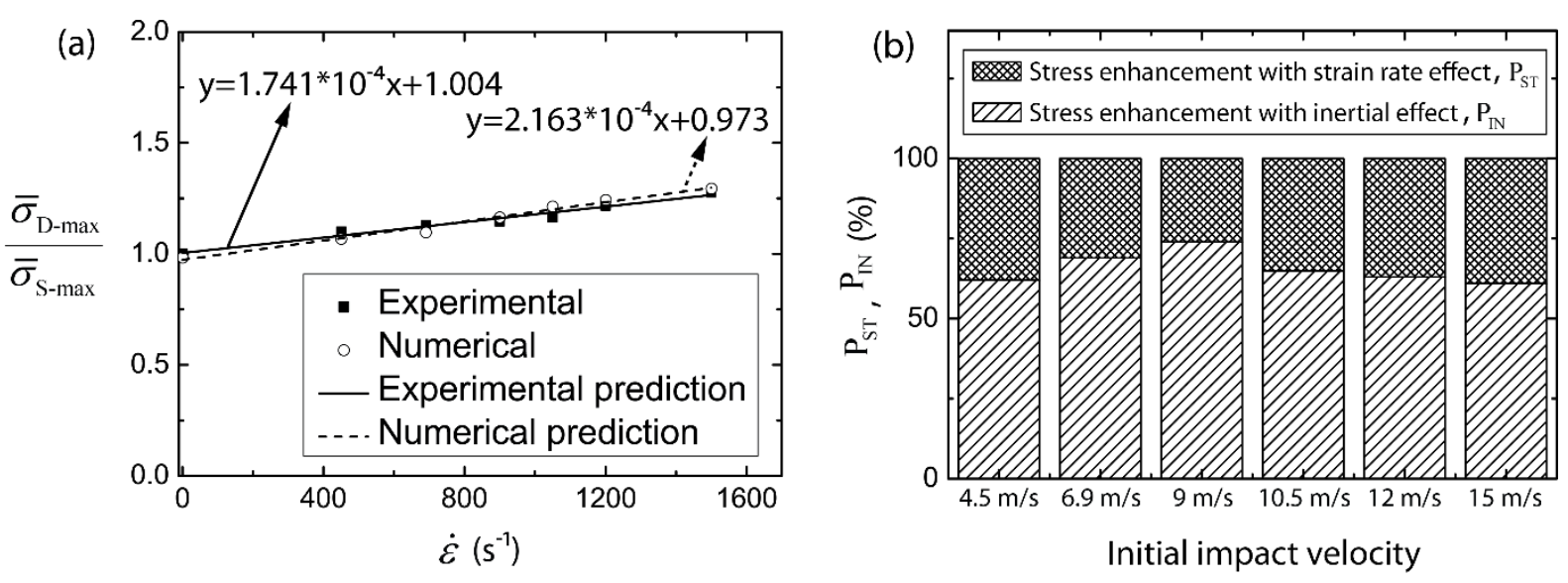

Figure 12

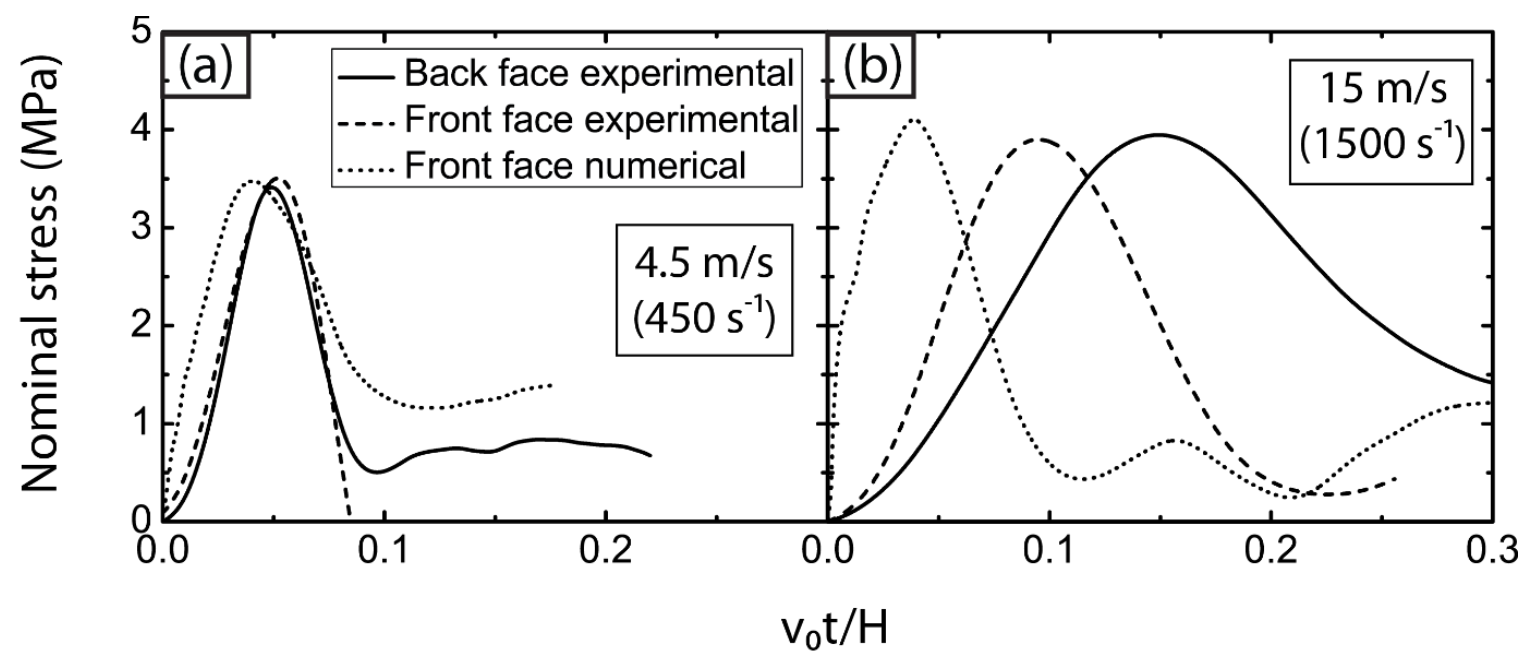

Figure 13 


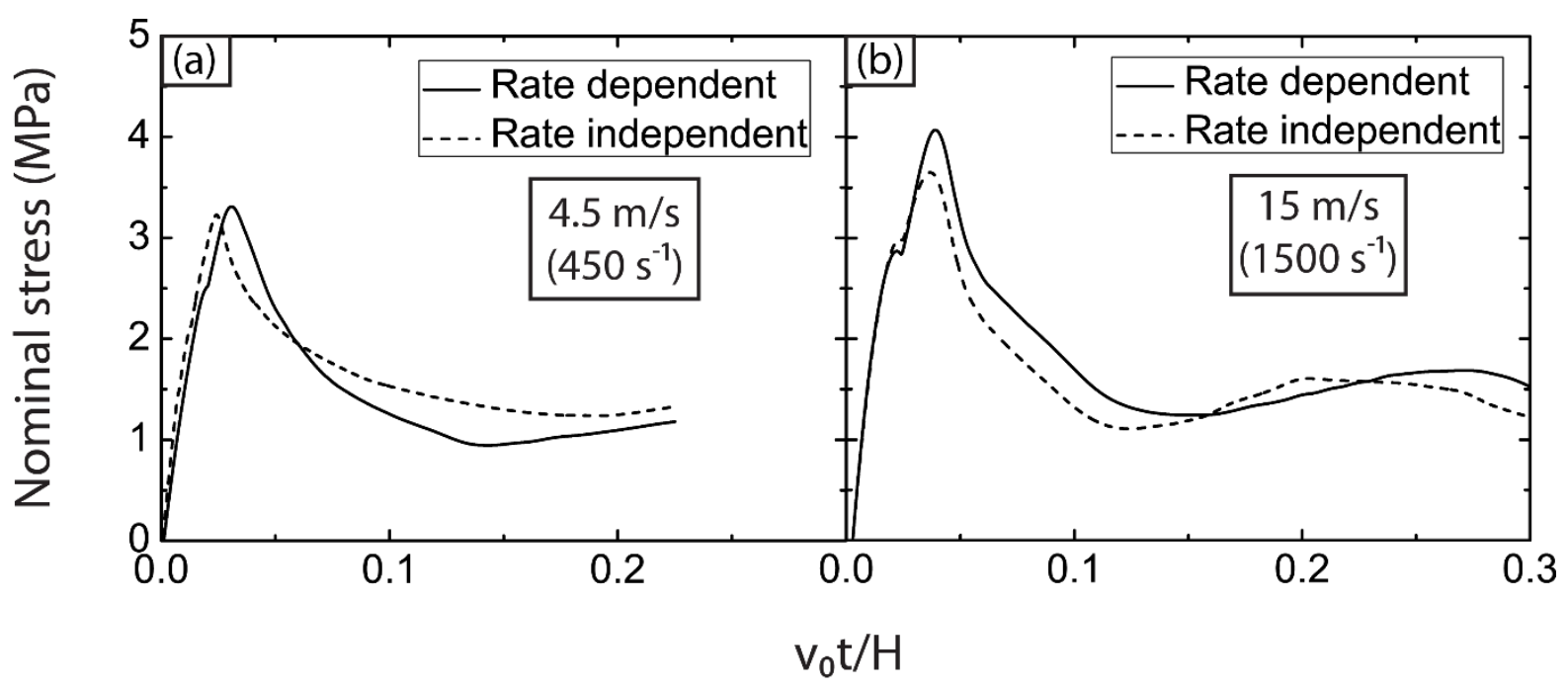

Figure 14

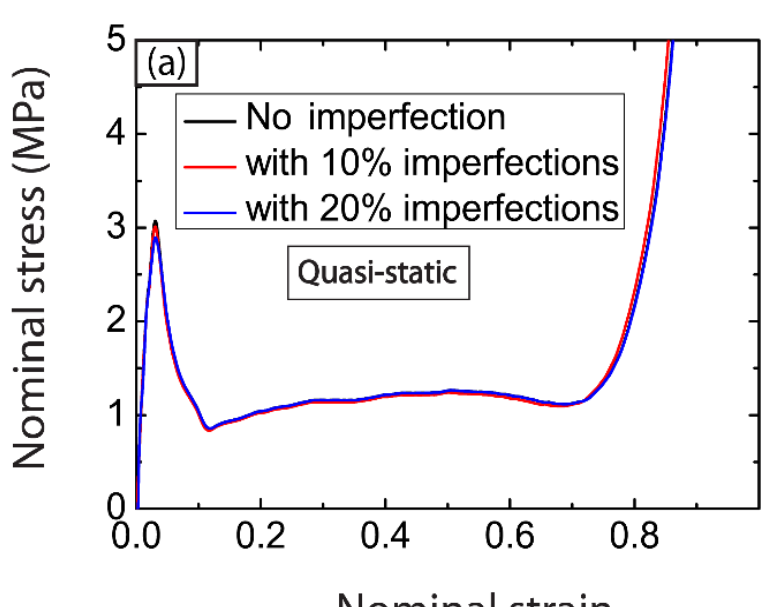

Nominal strain

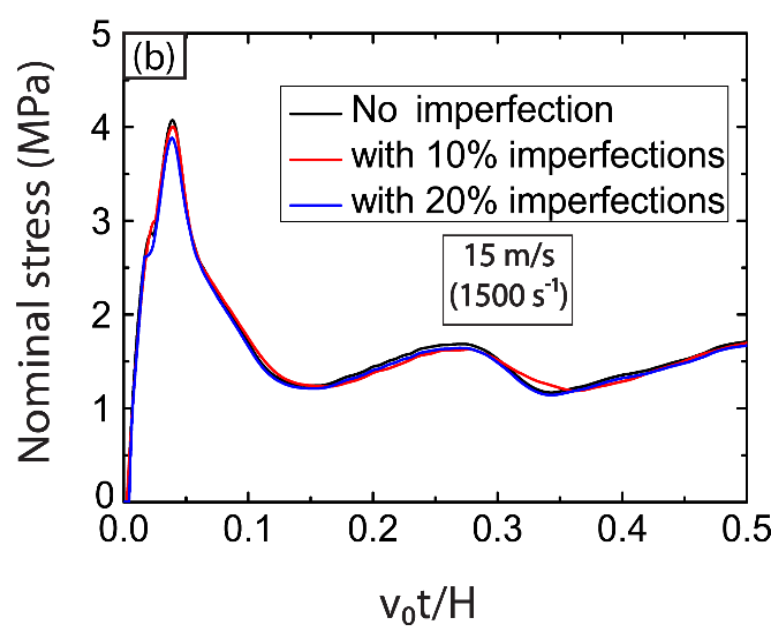

Figure 15

[1] McShane GJ, Radford DD, Deshpande VS, Fleck NA. The response of clamped sandwich plates with lattice cores subjected to shock loading. European Journal of Mechanics - A/Solids. 2006;25:215-29.

[2] Radford DD, Fleck NA, Deshpande VS. The response of clamped sandwich beams subjected to shock loading. International Journal of Impact Engineering. 2006;32:968-87. [3] Radford DD, McShane GJ, Deshpande VS, Fleck NA. The response of clamped sandwich plates with metallic foam cores to simulated blast loading. International Journal of Solids and Structures. 2006;43:2243-59. 
[4] Uth T, Deshpande VS. Response of clamped sandwich beams subjected to highvelocity impact by sand slugs. International Journal of Impact Engineering. 2014;69:16581.

[5] Fleck NA, Deshpande VS. The Resistance of Clamped Sandwich Beams to Shock Loading. Journal of Applied Mechanics. 2004;71:386-401.

[6] Liu T, Fleck NA, Wadley HNG, Deshpande VS. The impact of sand slugs against beams and plates: Coupled discrete particle/finite element simulations. Journal of the Mechanics and Physics of Solids. 2013;61:1798-821.

[7] Russell BP, Liu T, Fleck NA, Deshpande VS. The soft impact of composite sandwich beams with a square-honeycomb core. International Journal of Impact Engineering. 2012;48:65-81.

[8] Bourbigot $S$, Flambard $X$. Heat resistance and flammability of high performance fibres: A review. Fire and Materials. 2002;26:155-68.

[9] Zhou J, Yao Z, Chen Y, Wei D, Wu Y, Xu T. Mechanical and thermal properties of graphene oxide/phenolic resin composite. Polymer Composites. 2013;34:1245-9.

[10] Shafizadeh JE, Seferis JC. Characterization of phenolic resin for composite honeycomb applications. ICCM-12. Pairs1999.

[11] Kandola BK, Krishnan L, Deli D, Ebdon JR. Blends of unsaturated polyester and phenolic resins for application as fire-resistant matrices in fibre-reinforced composites. Part 2: Effects of resin structure, compatibility and composition on fire performance. Polymer Degradation and Stability. 2015;113:154-67.

[12] Heimbs S, Schmeer S, Middendorf P, Maier M. Strain rate effects in phenolic composites and phenolic-impregnated honeycomb structures. Composites Science and Technology. 2007;67:2827-37.

[13] Liu L, Wang H, Guan Z. Experimental and numerical study on the mechanical response of Nomex honeycomb core under transverse loading. Composite Structures. 2015;121:304-14.

[14] Aktay L, Johnson AF, Kröplin B-H. Numerical modelling of honeycomb core crush behaviour. Engineering Fracture Mechanics. 2008;75:2616-30.

[15] Seemann R, Krause D. Numerical modelling of Nomex honeycomb cores for detailed analyses of sandwich panel joints. 11th World Congress on Computational Mechanics. Barcelona, Spain2014.

[16] Anagnostopoulos K, Kim H. Phenomenological investigation of Nomex core damage mechanics in honeycomb sandwich panels under transverse impact and quasi-static loading. 31st Annual Technical Conference of the American Society for Composites. Virginia, USA2016.

[17] Asprone D, Auricchio F, Menna C, Morganti S, Prota A, Reali A. Statistical finite element analysis of the buckling behavior of honeycomb structures. Composite Structures. 2013;105:240-55.

[18] Zhang J, Ashby MF. The out-of-plane properties of honeycombs. International Journal of Mechanical Sciences. 1991;34:475-89.

[19] Ashby MF, Bréchet YJM. Designing hybrid materials. Acta Materialia. 2003;51:5801-21.

[20] Russell BP, Deshpande VS, Wadley HNG. Quasi-static deformation and failure modes of composite square honeycombs. Journal of Mechanics of Materials and Structures. 2008;3:1315-40.

[21] Russell BP, Liu T, Fleck NA, Deshpande VS. Quasi-Static Three-Point Bending of Carbon Fiber Sandwich Beams With Square Honeycomb Cores. Journal of Applied Mechanics. 2011;78:031008. 
[22] Marasco AI, Cartié DDR, Partridge IK, Rezai A. Mechanical properties balance in novel Z-pinned sandwich panels: Out-of-plane properties. Composites Part A: Applied Science and Manufacturing. 2006;37:295-302.

[23] Roy R, Park S-J, Kweon J-H, Choi J-H. Characterization of Nomex honeycomb core constituent material mechanical properties. Composite Structures. 2014;117:255-66.

[24] Foo CC, Chai GB, Seah LK. Mechanical properties of Nomex material and Nomex honeycomb structure. Composite Structures. 2007;80:588-94.

[25] Liu L, Meng P, Wang H, Guan $Z$. The flatwise compressive properties of Nomex honeycomb core with debonding imperfections in the double cell wall. Composites Part B: Engineering. 2015;76:122-32.

[26] Keshavanarayana S, Thotakuri MV. Off-axis compression behaviour of honeycomb core in WT-plane. International Journal of Crashworthiness. 2009;14:173-81.

[27] Harrigan JJ, Reid SR, Peng C. Inertia effects in impact energy absorbing materials and structures. International Journal of Impact Engineering. 1999;22:955-79.

[28] Su XY, Yu TX, Reid SR. Interial-sensitive impact energy-absorption structures. Part I: effect of inertia and elasticity. International Journal of Impact Engineering. 1995;16:651-72.

[29] Su XY, Yu TX, Reid SR. Inertia-sensitive impact energy-absorbing structures. Part II: effect of strain rate. International Journal of Impact Engineering. 1995;16:673-89.

[30] Radford DD, McShane GJ, Deshpande VS, Fleck NA. Dynamic Compressive Response of Stainless-Steel Square Honeycombs. Journal of Applied Mechanics. 2007;74:658-67.

[31] Park S, Russell BP, Deshpande VS, Fleck NA. Dynamic compressive response of composite square honeycombs. Composites Part A: Applied Science and Manufacturing. 2012;43:527-36.

[32] Liu T, Turner P. Dynamic compressive response of wrapped carbon fibre composite corrugated cores. Composite Structures. 2016.

[33] Abrate S, Castanié B, Rajapakse YDS. Dynamic Failure of Composite and Sandwich Structures. New York: Springer, 2012.

[34] Penado FE. Effective Elastic Properties of Honeycomb Core with Fiber-Reinforced Composite Cells. Open Journal of Composite Materials. 2013;03:89-96.

[35] Gibson LJ, Ashby MF. Cellular solids: structure and properties. Cambridge, UK: Cambridge University Press, 1997.

[36] Kolsky H. An Investigation of the Mechanical Properties of Materials at very High Rates of Loading. Proceedings of the Physical Society Section B. 1949;62:676-700.

[37] Zhang Y, Liu T, Ren H, Maskery I, Ashcroft I. Dynamic compressive response of additively manufactured AISi10Mg alloy hierarchical honeycomb structures. Composite Structures. 2018.

[38] Park S, Uth T, Fleck NA, Wadley HNG, Deshpande VS. Sand column impact onto a Kolsky pressure bar. International Journal of Impact Engineering. 2013;62:229-42.

[39] ABAQUS. ABAUQS analysis user's manual, Version 6.14, ABAQUS, Inc. 2014.

[40] W J, Jr D, Newell JA. Characterization of structural changes in thermally enhanced Kevlar-29 fiber. Journal of Applied Polymer Science. 2003;91:417-24.

[41] Kilchert SV. Nonlinear finite element modelling of degradation and failure in folded core composite sandwich structures: University of Stuttgart, 2013.

[42] NagarajaRao N, Lohrmann M, Tall L. Effect of strain rate on the yield stress of structural steel. ASTM Journal of Materials. 1966;1:1684-737.

[43] Warrior NA, Fernie R, Jones IA. High strain rate tensile and compressive testing of braided composite materials. 2003 SEM Annual Conference \& Exposition on Experimental and Applied mechanics. Charlotte, North Carolina2003. 
